\title{
Correction to: Clinical Outcomes and Evaluation of Laparoscopic Proximal Gastrectomy with Double-Flap Technique for Early Gastric Cancer in the Upper Third of the Stomach
}

Masaru Hayami, MD, PhD, Naoki Hiki, MD, PhD, Souya Nunobe, MD, PhD, Shinji Mine, MD, Manabu Ohashi, MD, PhD, Koshi Kumagai, MD, PhD, Satoshi Ida, MD, PhD, Masayuki Watanabe, MD, PhD, Takeshi Sano, MD, PhD, and Toshiharu Yamaguchi, MD, PhD

Department of Gastroenterological Surgery, Cancer Institute Hospital, Japanese Foundation for Cancer Research, Tokyo, Japan

\section{CORRECTION TO: ANN SURG ONCOL (2017) 24:1635-1642}

HTTPS://DOI.ORG/10.1245/S10434-017-5782-X

In the original article on page 1636, first line, the reference cited for Kamikawa et al. is incorrect. The correct reference is as follows:

Kamikawa Y, Kobayashi T, Kamiyama S, et al. A new procedure of esophagogastrostomy to prevent reflux following proximal gastrectomy (in Japanese). Shoukakigeka. 2001;24:1053-60.

The original article can be found online at https://doi.org/10.1245/ s10434-017-5782-x.

(C) Society of Surgical Oncology 2018

Published Online: 17 May 2018

N. Hiki, MD, PhD

e-mail: naoki.hiki@jfcr.or.jp 